\title{
Pessoas (transexuais): dimensões sociais de vidas (in)determinadas pela ciência
}

\author{
Vidas que desafiam corpos e \\ sonhos: uma etnografia do \\ construir-se outro no gênero e na \\ sexualidade.
}

TEIXEIRA, Flavia do Bonsucesso.

2009. 243 f. Tese (Doutorado em Ciências Sociais) - Programa de Pós-Graduação em Ciências Sociais, Universidade Estadual de Campinas - Unicamp, Campinas, 2009.

Contextualizar as dimensões históricas, sociais, políticas e culturais da construção do gênero e das sexualidades constitui o trajeto trilhado por essa antropóloga. Professora adjunta da Faculdade de Medicina da Universidade Federal de Uberlândia - UFU, Flávia do Bonsucesso Teixeira é graduada em Terapia Ocupacional (1991) e especialista em Sociologia e Educação e Movimento Humano (1994).

No mestrado em Educação, pela UFU (2000), investigou a constituição de papéis masculinos e femininos e a conotação de valores construídos em torno deles na educação infantil. No doutorado em Ciências Sociais, pela Unicamp (2009), enfocou sujeitos que buscavam a cirurgia de transgenitalização. Vinculada a esta mesma instituição, investigou no pós-doutorado (2010) o processo de migração de travestis brasileiras para a Itália, ressaltando prostituição e conjugalidades.

Sustentando o argumento de que a forma como as instituições médico-jurídicas reconhecem as pessoas (transexuais) coloca em risco suas possibilidades de sobrevivência e sua efetivação como seres humanos, Flávia Teixeira teve como objetivo no doutorado "compreender as possibilidades e estratégias da atuação dos sujeitos que buscavam a cirurgia de transgenitalização" (p. 19).

Sob uma abordagem etnográfica e ancorada nos estudos queer, a autora se utilizou de fontes bibliográficas, documentais, entrevistas e observações. Analisou 29 processos judiciais destinados à autorização para a realização da cirurgia de transgenitalização no Brasil, enfatizando os discursos médicos e jurídicos. $O$ acesso a esse material se deu pelo Programa de Transgenitalização, coordenado pela Promotoria de Justiça Criminal de Defesa dos Usuários dos Serviços de Saúde (Pró-Vida), do Ministério Público do Distrito Federal e Territórios, criado em 1999 e suspenso em 2004.

Dezesseis pessoas (transexuais) definiram o universo empírico do estudo, sendo oito inscritas/ os no Programa, sete do movimento social e uma mulher (transexual) que, anterior ao PróVida, havia se submetido à cirurgia no exterior. O trabalho de campo não se restringiu às entrevistas. Visitas a residências, hospital, locais de trabalho e lazer e a participação em espaços de discussão política compuseram o processo.

Subsidiada pela teoria foucaultiana, o processo de análise das entrevistas é compreendido pela autora como um momento de autoavaliação vivenciado pelos sujeitos em que se podem aflorar tensões e autocríticas, ultrapassando as fronteiras do "dito".

A compreensão e a articulação dos saberes médicos legais com relação à transexualidade foram o tema do primeiro capítulo: "O natural também é uma pose". A autora utilizou como fonte principal documentos do Conselho Federal de Medicina e pareceres e sentenças judiciais, uma vez que seus discursos compunham o Programa Pró-Vida. As possíveis origens biológicas da homossexualidade defendidas por pesquisas do século $\mathrm{XX}$, como enfatiza Teixeira, "emprestaram suas (in)certezas para compor um léxico explicativo para a transexualidade" (p. 32).

O segundo capítulo é dedicado à análise dos processos das pessoas (transexuais) que recorreram ao Pró-Vida em busca da autorização para a realização da cirurgia de transgenitalização. Evidenciou-se a disputa entre o saber-poder médico e jurídico, que, ao mesmo tempo que define a legitimidade do/a "verdadeiro/a transexual", exerce uma "violência institucional" ao impedir "o outro de dizer quem é".

Ressalta-se também a necessidade de "ressocialização" das pessoas (transexuais) argumentada pelo discurso médico e jurídico por 
meio da cirurgia que, na verdade, se fundamenta muito mais nos aspectos biológicos do que nos aspectos sociais que constituem o cotidiano desses sujeitos. O título deste capítulo, "Não basta abrir a janela...", expressa coerentemente as contextualizações apresentadas.

O terceiro capítulo, "Histórias que não têm era uma vez...", problematiza os saberes e as normas determinantes da fixidez da transexualidade como patologia em oposição às "diversas possibilidades de vidas e a fluidez de suas experiências" (p. 33). Através de fragmentos das entrevistas e das observações realizadas no período de 2004 a 2008, a autora tenta capturar instantes do cotidiano desses sujeitos, enfocando suas vivências sociais nos espaços familiares, escolares, profissionais, afetivos etc.

Os desafios enfrentados na luta pelo reconhecimento político das pessoas (transexuais) são o foco do quarto capítulo: "Diálogos que disfarçam conflitos por explodir". Ao mesmo tempo que se busca uma identidade social da transexualidade fora dos parâmetros patológicos, persistem os impasses nas negociações de políticas públicas com o Ministério da Saúde para esse segmento, que, de certa forma, mantém sua legitimidade ainda ancorada num diagnóstico médico-jurídico. Em contrapartida, Teixeira argumenta que

A transexualidade pode ser lida como uma experiência de mobilidade que carrega um desejo de finitude. Alcançar a "outra margem do rio" e declarar o fim desta passagem. [...] A questão maior é que a armadilha desse discurso reside no caminho escolhido para alcançar a outra margem do rio: a imposição da cirurgia (p. 193).

As tensões vivenciadas no movimento político responsáveis pelo distanciamento entre travestis e transexuais, o desejo de parte das mulheres (transexuais) em aderir ao movimento feminista e as restrições com relação à adesão dos homens (transexuais) ao Pró-Vida integram também as contextualizações deste capítulo.

Como resultados, Flávia Teixeira aponta para a problematização da legitimidade social atribuída à experiência das pessoas (transexuais) precedente e exclusivamente conferida pelo discurso médico-jurídico. Ao contrário de implementar novas formas e sentidos ao sentimento de "ser diferente", esses discursos e práticas reafirmam esses sujeitos como em "desacordo", protagonistas de um "engano" ou personificadores/as de uma "fraude". Em decorrência disso, condiciona-se a transexualidade a "uma visão essencialista e dicotômica do gênero", assim como desencadeia mecanismos que ampliam a fragilidade dos movimentos sociais em suas lutas.

Ao seguir as pistas deixadas por Berenice Bento, ${ }^{1}$ que primeiramente se preocupou com a problematização e a (des)construção do conceito de transexualidade fundamentado como processo patológico, a autora entrelaça essa problemática aos contextos de suas vivências cotidianas. A família, a escola, o trabalho, o lazer, a afetividade, o movimento social, correlacionados a essa possibilidade de construção do gênero, passam a tecer um sujeito integral, complexo, múltiplo, dono de uma história particular. Esse fato ressalta uma das principais contribuições deste estudo, por se dedicar aos aspectos da subjetividade das pessoas (transexuais) e não somente pelas dimensões biológicas da readequação genital.

A relevância da pesquisa abrange tanto o meio acadêmico como o movimento social. Oferece à academia uma riqueza de subsídios teóricos que contemplam as mais diversas áreas de conhecimento. Destaco o campo educacional, uma vez que as vivências escolares relatadas pelos sujeitos conceberam maior sentido às afirmativas de Sérgio Carrara e Silvia Ramos, ${ }^{2}$ quando destacam que a baixa incidência de discriminação e preconceito contra travestis e transexuais em instituições de ensino deve-se ao fato de que esses sujeitos pouco frequentam escolas e faculdades. A escola torna-se, na maioria das vezes, um lugar inabitável para essas pessoas.

Com relação ao movimento social, parte do material empírico foi construído na participação em espaços de encontro, discussão e elaboração de pautas políticas referentes à população de travestis e transexuais. O Encontro Nacional de Travestis e Transexuais na Luta contra a Aids - ENTLAIDS foi um dos principais. Nesse sentido, o estudo potencializa novas reflexões e direcionamentos envolvendo questões em pauta pelo segmento, tais como a patologização da transexualidade, as divergências e tensões entre travestis $e$ transexuais, o nome social, a prostituição etc.

Concluindo, a tese é indicada para o mais variado público, acadêmico ou não, desde integrantes dos movimentos sociais até estudantes de graduação ou pós-graduação das mais variadas áreas do conhecimento que tenham interesse em compreender um pouco do universo da transexualidade.

Por explorar com densidade a multiplicidade de elementos que compõem a consti- 
tuição do gênero e das sexualidades fora dos padrões essencialistas e normativos, a leitura de obras como $O$ que é transexualidade, de Berenice Bento, ${ }^{3}$ e Um corpo estranho: ensaios sobre sexualidade e teoria queer, de Guacira Lopes Louro, ${ }^{4}$ fornecem elementos teóricos que auxiliam numa melhor compreensão do trabalho.

Afinal, como afirma Flávia Teixeira, "a experiência transexual materializa incertezas que se fundem com as questões pautadas em outros espaços" (p. 229), sendo a construção identitária um processo de mutação e a identificação de gênero, consequentemente, uma aproximação do que ele realmente seja.

\section{Notas}

' Berenice BENTO, 2003.

${ }^{2}$ Sérgio CARRARA e Silvia RAMOS, 2005.

${ }^{3}$ BENTO, 2008

${ }^{4}$ Guacira Lopes LOURO, 2004.

\section{Referências bibliográficas}

BENTO Berenice. A reinvenção do corpo: sexualidade e gênero na experiência transexual. 2003. Tese (Doutorado em Sociologia) - Departamento de Sociologia, Universidade de Brasília, Brasília, 2003.

. O que é transexualidade? São Paulo: Brasiliense, 2008. (Primeiros Passos).

CARRARA, Sérgio; RAMOS; Silvia. Política, direitos, violência e homossexualidade: Pesquisa 9a. Parada do Orgulho GLBT - Rio 2004. Rio de Janeiro: Cepecs, 2005. Disponível em: <www.clam.org.br/>. Acesso em: 2 nov. 2007.

LOURO, Guacira Lopes. Um corpo estranho: ensaios sobre sexualidade e teoria queer. Belo Horizonte: América, 2004. 90 p.

Neil Franco

Universidade Federal de Mato Grosso (Médio Araguaia) 